Revista de Ciencias Sociales - Número 69 (2016) - Páginas 13-52

La jurisprudencia del multiculturalismo en Chile...

\title{
LA JURISPRUDENCIA DEL MULTICULTURALISMO EN CHILE: LA CONSULTA PREVIA INDÍGENA ANTE TRIBUNALES
}

\author{
THE JURISPRUDENCE OF MULTICULTURALISM \\ IN CHILE: INDIGENOUS PRIOR \\ CONSULTATION IN COURT
}

\author{
MATÍAS MEZA-LOPEHANDÍA G** \\ Investigador de la Biblioteca del Congreso Nacional \\ elcorreodematias@gmail.com
}

\section{Resumen}

Este artículo defiende la idea que el Convenio 169 de la OIT, y la consulta previa en él consagrada, es una respuesta del liberalismo multicultural al problema de la diversidad cultural. Por lo anterior, su interpretación y aplicación debe hacerse a la luz de dicha caracterización. Al revisar las decisiones que en esta materia han adoptado los tribunales superiores de justicia, se constata un déficit de comprensión, que podría explicar la existencia de decisiones erráticas e inconsistentes con el estándar internacional.

* MSc en Derechos Humanos en London School of Economics and Political

Science. Dirección postal: San Juan de Dios 634, Valparaíso. El autor agradece los comentarios de Luis Villavicencio y Sergio Fuenzalida. Artículo recibido el 24 de octubre de 2016 y aceptado el 25 de noviembre de 2016.

Revista de Ciencias Sociales - Número 69 (2016) - Universidad de Valparáíso - ISSN 0716-7725-Valparaíso, Chile 


\title{
Palabras clave
}

Multiculturalismo liberal, consulta previa, Convenio 169.

\begin{abstract}
This article defends the idea that indigenous prior consultation as stipulated in ILO Convention $\mathrm{N}^{\circ} 169$, is an answer to cultural diversity issues provided within the framework of multicultural liberalism. Hence, this should be bared in mind in interpreting it. After reviewing high court's decisions on the matter, a deficit is found, which could explain erratic decisions that could offend international standards.
\end{abstract}

\section{Keywords} $\mathrm{N}^{\circ} 169$

Liberal multiculturalism, indigenous prior consultation, Convention

\section{Introducción}

Este artículo revisa críticamente un conjunto de sentencias de los tribunales superiores sobre la aplicación de la consulta previa en el contexto chileno ${ }^{1}$. El examen se realiza a partir de la idea que el Convenio 169 de la OIT, y la consulta previa en él consagrada, es una respuesta del multiculturalismo liberal al problema de la diversidad cultural. Esta perspectiva busca iluminar el sinuoso itinerario que ha recorrido la consulta previa ante la judicatura chilena, y contribuir a un entendimiento más acabado del significado que la incorporación de esta institución tiene en el ordenamiento jurídico.

Pare ello, se comienza fundamentando la adscripción del Convenio 169 al multiculturalismo liberal, y se explica el rol que cumple la consulta previa indígena en el entramado de dicho instrumento internacional. A la luz de lo anterior, se examina la jurisprudencia en

1. Se revisaron más de cincuenta sentencias, dictadas por tribunales superiores entre septiembre de 2009 y 2016, obtenidas de la base de jurisprudencia del poder judicial. Se agradece a Consuelo Montecinos y Pablo Rubio por su ayuda en su recolección. Por razones de espacio, solo se incluyen las sentencias citadas.

Facultad de Derecho y Ciencias Sociales - Universidad de Valparaíso - Chile 
materia de consulta previa, particularmente la medida en que se ha reconocido como un mecanismo de participación de características propias, y la disposición de aquella para concebir la afectación directa desde una perspectiva multicultural.

\section{E1 Convenio 169 como instrumento del multiculturalismo liberal}

Desde los orígenes del derecho internacional, la relación entre los pueblos indígenas y los Estados en que habitan ha estado marcada por la exclusión y la negación de derechos. De hecho, un primer momento de reconocimiento de la humanidad de los indígenas en la jurisprudencia de los precursores del derecho internacional como Vitoria y Grocio, fue seguido de la justificación de la conquista y la desposesión ${ }^{2}$. Luego, la cuestión indígena fue convertida en un problema doméstico, sin significación internacional.

Esta característica genética, continuó tras la Gran Guerra (19141919), y el establecimiento de Sociedad de las Naciones ${ }^{3}$, y se actualizó en la configuración de nuevo orden mundial tras la Segunda Guerra Mundial. En esta ocasión, los indígenas fueron marginados del proceso de descolonización ${ }^{4}$, asignándoseles un estatuto de protección orientado

2. Anaya (2000); Anghie (2007). ANAYA, James: Indigenous Peoples in International Law, Oxford University Press,Nueva York, 2000; ANGHIE, Anthony: Imperialism, Sovereignty and the Making of International Law, Cambridge University Press, Cambridge

3. Este tercer momento de exclusión se grafica en el reclamo presentado por un vocero indígena de Norteamérica ante la Sociedad de las Naciones, para el reconocimiento de la libre determinación a su pueblo, prometida por el presidente Wilson a todos los pueblos. El asunto nunca fue abordado, siendo considerado una cuestión doméstica entre el Imperio Británico y Canadá Niezen (2003).

4. La descolonización se limitará a los territorios fideicometidos del artículo 77 de la Carta de NN.UU. y a los territorios no autónomos de su capítulo XI.

Los primeros se referían a los mandatos de la extinta Liga de las Naciones y los segundos fueron definidos como aquellos que estuvieran separados geográficamente del país que los administrara, y que tuvieran diferencias étnicas o culturales con aquel (principio IV, resolución 1541-XV de 1960 de la Asamblea General de Naciones Unidas).

Revista de Ciencias Sociales - Número 69 (2016) - Universidad de Valparáíso - ISSN 0716-7725-Valparaíso, Chile 
a la asimilación, heredado de la era del imperialismo, materializado en el Convenio 107 de la OIT de $1957^{5}$.

De esta manera, cuando en 1989 la Conferencia Internacional del Trabajo adoptó el Convenio 169 de la OIT, la comunidad internacional buscaba rectificar el modo en que había afrontado históricamente la cuestión de los pueblos indígenas.

El nuevo instrumento fue explícitamente adoptado "a fin de eliminar la orientación hacia la asimilación de las normas anteriores" Consecuentemente, el Convenio busca asegurar que las medidas que se adopten para promover los derechos individuales y colectivos de los indígenas se realicen "respetando su identidad social y cultural, sus costumbres y tradiciones, y sus instituciones", lo que contrasta con la subordinación de la protección de la diversidad cultural al objetivo de la asimilación presente en su antecesor, y con el carácter temporal de las medidas contemplados en aquel ${ }^{7}$. En este sentido, la percepción de la diversidad cultural (indígena) como un valor a ser protegido y promovido, junto con el consecuente reconocimiento del carácter colectivo del sujeto de los derechos (los pueblos indígenas), constituyen la radical novedad del Convenio 169.

Este cambio de paradigma explica la centralidad que el Convenio otorga a tres cuestiones estrechamente relacionadas entre sí. Primero, la protección y reconocimiento de la propiedad y posesión indígena sobre sus tierras, entendidas no sólo como la superficie continua y delimitada reconocida en el Código Civil, sino como "la totalidad del

5. El carácter asimilacionista de la integración promovida por el Convenio 107, se evidencia en los límites que éste impone a la protección de la diferencia cultural, como su compatibilidad con "los programas de integración" o con "su desarrollo económico y social” (arts. 7.2 y 13). Por otra parte, el artículo 3 establece el carácter temporal de esas medidas de protección (art. 3). La resonancia con la lógica imperialista se evidencia al comparar la orientación proteccionista e integracionista del Convenio 107 con las disposiciones relativas a la protección de los nativos establecidas en la Conferencia de Berlín (1884-1885), instancia en que las potencias europeas se repartieron África, en particular su artículo $6^{\circ}$ (Berlin Conference, 1909).

6. Preámbulo $\mathrm{C}^{\circ} 169$.

7. Ver nota 5.

Facultad de Derecho y Ciencias Sociales - Universidad de Valparaíso - Chile 
hábitat" que ocupan de alguna manera (art. 13.2), lo que incluye derechos de utilización, administración y conservación de los recursos naturales presentes en dichos territorios (art. 15.2). Esto, por cuanto el propio Convenio reconoce "la importancia especial que para las culturas y valores espirituales de los pueblos interesados reviste su relación con las tierras o territorios [...] que ocupan o utilizan de alguna otra manera, y en particular los aspectos colectivos de esa relación" (art. 13.1) ${ }^{8}$. En segundo lugar, el Convenio reconoce ciertos ámbitos de autonomía, particularmente en materia de justicia penal (art. 9.1) y prestación de servicios asociados a la satisfacción de derechos sociales (arts. 25 y 27.2). Finalmente, el Convenio instituye la obligatoriedad de la consulta previa indígena "cada vez que se prevean medidas legislativas o administrativas susceptibles de afectarles directamente" (art. 6.2), lo cual ha sido considerado, entre otros, por la propia OIT, como la "piedra angular del Convenio". En este sentido, la Corte Interamericana de Derechos Humanos (Corte IDH) ha señalado que "[e]l reconocimiento del derecho a la consulta de las comunidades y pueblos indígenas y tribales está cimentado, entre otros, en el respeto a sus derechos a la cultura propia o identidad cultural [...], los cuales deben ser garantizados, particularmente, en una sociedad pluralista, multicultural y democrática" ${ }^{10}$.

8. La idea que los pueblos indígenas constituyen su identidad en su relación con su hábitat también ha sido recogida por instancias internacionales de adjudicación. Ver la seminal sentencia de la Corte IDH, AwasTingni v. Nicaragua (2001), especialmente párr. 149. En la legislación chilena, el "Estado reconoce que los indígenas de Chile [...] conservan manifestaciones étnicas y culturales propias siendo para ellos la tierra el fundamento principal de su existencia y cultura" (art. 1 Ley $\mathrm{N}^{\circ}$ 19.253). Sobre los diversos organismos internacionales que han seguido este mismo razonamiento, consultar Meza-Lopehandía (2013).

9. ANAYA, James: "Informe del Relator Especial sobre la situación de los derechos humanos y las libertades fundamentales de los indígenas", 2009, A/HRC/12/34/

Add.6. Disponible en: http://goo.gl/o9lnG6. Fecha de consulta: 25 de julio de 2016; OIT (2009) p. 731. Por su parte, la Corte IDH ha ratificado la obligatoriedad de la consulta previa indígena y su particular conexión con el derecho a la identidad cultural en su sentencia de fondo en el caso Sarayaku v. Ecuador (2012), especialmente párr. 159.

10. Sarayaku v. Ecuador (2012): párr. 159.

Revista de Ciencias Sociales - Número 69 (2016) - Universidad de Valparáíso - ISSN 0716-7725-Valparaíso, Chile 
Ahora bien, ¿̇uál es el nuevo paradigma al que hacemos referencia y que le da coherencia y legitimidad a los nuevos derechos reconocidos? Se trata de la consagración normativa del multiculturalismo de raigambre liberal, esto es, el intento de acomodar la diversidad cultural aportada por los indígenas al interior de los Estados, a través de una lectura étnicamente contextualizada de los derechos individuales. Se trata de una solución multicultural, en tanto considera la diversidad cultural, en particular la identidad indígena, como un valor a ser promovido y protegido, como se desprende claramente de las diversas disposiciones ya citadas. A su vez, es liberal en tanto la justificación implícita de los derechos colectivos reconocidos en el Convenio está en el rescate de la autonomía individual auténtica ${ }^{11}$.

Esto último se desprende de dos cuestiones. Primero, del hecho que el Convenio supedita lo colectivo a la superioridad moral del individuo, al establecer en general, que el derecho a conservar sus costumbres e instituciones encuentran su límite en aquellos derechos "definidos por el sistema jurídico nacional" y en "los derechos humanos internacionalmente reconocidos" (arts. 8.2 y 9.1), esto es, en lo que la doctrina ha denominado bloque de derechos constitucionales, lo que incluye los derechos individuales ${ }^{12}$. Esto es consistente con una teoría liberal de los derechos colectivos, que puede justificarlos como protecciones externas, o sea, como derechos del grupo para protegerse del poder político y económico de la sociedad dominante; mas no como restricciones internas, o sea, como derechos del grupo sobre sus miembros ${ }^{13}$.

11. El multiculturalismo puede ser iliberal cuando dota de valor intrínseco a la comunidad, abriendo así el camino a la restricción o supresión de derechos individuales en pos del ejercicio de derechos colectivos.

12. Sobre el bloque de constitucionalidad, por todos, Nogueira, Héctor: "Las constituciones y los tratados en materia de derechos humanos: América Latina y Chile", Ius et Praxis, vol. 6 No 2, 2000, pp. 227-279.

13. KYMLICKA, Will: Ciudadanía multicultural: una teoría liberal de los derechos de las minorías, Paidós, Madrid, 1996.

Facultad de Derecho y Ciencias Sociales - Universidad de Valparaíso - Chile 
En segundo lugar, y esto es decisivo para afirmar el carácter liberal de la protección y reconocimiento de derechos indígenas, los organismos internacionales de adjudicación han entendido la protección ofrecida de un modo que ratifica que lo protegido a través del reconocimiento de derechos colectivos es, en última instancia, el goce efectivo de derechos individuales. En este sentido, la Corte IDH ha extendido la protección de la propiedad garantizada en el artículo 21 de la Convención Americana de Derechos Humanos, formulada en evidentes términos individualistas ${ }^{14}$, hasta proteger la propiedad y posesión comunal indígena, pues de lo contrario "significaría hacer ilusoria la protección del artículo 21 de la Convención para millones de personas" ${ }^{15}$. O sea, se reconoce que, para que los indígenas puedan gozar de su derecho a la propiedad, debe protegerse la propiedad del modo en que ellos la conciben, esto es, de un modo colectivo. Para arribar a esta conclusión, la Corte ha apelado explícitamente al Convenio 169, especialmente el reconocimiento que dicho instrumento hace a la importancia especial de la relación de los indígenas con sus tierras y territorios ${ }^{16}$.

En este sentido, el Convenio 169, y su interpretación y aplicación internacional, busca salvaguardar la diversidad cultural reconociendo derechos colectivos a los pueblos indígenas para permitir la autonomía individual de los indígenas, y el necesario ejercicio de sus derechos individuales. Por eso el Convenio es, al mismo tiempo, multicultural y liberal.

Desde esta perspectiva, cuando el preámbulo de dicho instrumento observa "que en muchas partes del mundo esos pueblos no pueden gozar de los derechos humanos fundamentales en el mismo grado que el resto de la población de los Estados en que viven y que sus leyes, valores, costumbres y perspectivas han sufrido a menudo una erosión”, lo que está implícito es que los indígenas no gozan de los

14. Conforme al artículo 21 de la CADH, "[t] oda persona tiene derecho al uso y goce de sus bienes” y según su artículo 1.2, "persona es todo ser humano”.

15. Sawhoyamaxa v. Paraguay (2006): párr. 120.

16. Sawhoyamaxa v. Paraguay (2006):párr.117-121. Ver también AwasTingni v. Nicaragua (2001); Yakye Axa v. Paraguay (2005); y Sarayaku v. Ecuador (2012).

Revista de Ciencias Sociales - Número 69 (2016) - Universidad de Valparáíso - ISSN 0716-7725-Valparaíso, Chile 
derechos elementales porque su cultura ("leyes, valores, costumbres y perspectivas") ha sido erosionada. En otras palabras, el reconocimiento de la cultura societal se concibe como un requisito para el ejercicio de una autonomía individual auténtica, en la medida en que las decisiones individuales se toman en un contexto social determinado, que otorga valor y sentido a esas decisiones ${ }^{17}$. Por ello, si se le niega valor a dicho contexto, se corre el riesgo de impedir que los individuos puedan tomar decisiones significativas, que es, la meta última del liberalismo ${ }^{18}$.

De esta manera, el Convenio 169 supone una renuncia al agnosticismo étnico promovido por el liberalismo de viejo cuño, y conmina a los Estados a concebir la diversidad cultural como riqueza, y más aún, como un requisito para el ejercicio de una autonomía individual auténtica. Esto requiere un reacomodo institucional, en orden a permitir el ejercicio de derechos colectivos. No se trata simplemente, como sugiere Sierra ${ }^{19}$, de garantizar los derechos individuales universales a aquellos que históricamente han sido excluidos de su ejercicio mediante acción afirmativa, esencialmente transitoria, o de tomar medidas de justicia anamnésica, como el reconocimiento constitucional a los pueblos indígenas. Por el contrario, lo que se postula es el reconocimiento de lo que Kymlicka denomina derechos diferenciados en función del grupo ${ }^{20}$.

17. KYMLICKA, Will, ob. cit. En un sentido similar, TAYLOR, Charles: "El multiculturalismo y La política del reconocimiento": Fondo de Cultura Económica, México, ensayo, 1993. Entre nosotros Peña, Carlos: "Democracia y minorías”, Pensamiento Constitucional, vol. $7 \mathrm{~N}^{\circ}$ 7, 2000, pp. 387-417. Disponible en: http://goo.gl/YDT3fV. Fecha de consulta: 15 de enero de 2016; y Villavicencio, Luis: "La relevancia moral de la identidad cultural", Polis (Santiago), vol. $9 \mathrm{~N}^{\circ} 26$, 2010, pp. 339-420.

18. En este sentido, la Corte IDH ha señalado que para respetar el derecho a la igualdad ante la ley, "los Estados deben tomar en consideración las características propias que diferencian a los miembros de los pueblos indígenas de la población en general y que conforman su identidad cultural” Yakye Axa Vs. Paraguay, 2005: párr. 51.

19. SIERRA, Lucas: "La Constitución y los indígenas en Chile: Reconocimiento individual y no colectivo", Estudios Públicos, vol. 92, 2003, pp. 19-27.

20. KYMLICKA, Will. (1995). Multicultural Citizenship. Al Liberal Theory of Minority Rights. Clarendon Press, Oxford, pp. 26 ss.

Facultad de Derecho y Ciencias Sociales - Universidad de Valparaíso - Chile 
La jurisprudencia del multiculturalismo en Chile...

Entender el Convenio 169 como una concreción normativa del multiculturalismo liberal permite descartar las aprehensiones que ven en el reconocimiento de derechos colectivos a ciertos grupos, una negación de la tradición liberal, y particularmente, un atentado contra la noción de derechos, que sólo tendría sentido en su variante individual ${ }^{21}$. Asimismo lo dota de una coherencia que facilita su comprensión, particularmente en lo que se refiere al alcance y funcionamiento de la consulta previa indígena.

En este sentido, la consulta previa cumple dos funciones esenciales para la realización del proyecto del liberalismo multicultural. Por un lado, es uno de los mecanismos para garantizar la participación política de los indígenas. O sea, además de reafirmar el derecho de los indígenas a participar "por lo menos en la misma media que otros sectores de la población" en las políticas que les conciernen (art. 6.1 letra b), el Convenio establece la consulta para garantizar el derecho de participación política de los indígenas desde su especificidad, lo que implica una concepción colectiva de la participación ${ }^{22}$. En este sentido, la consulta previa es un derecho de participación de los pueblos indígenas que se ejercita a través de un procedimiento con determinadas

21. En este sentido, Sierra, ob. cit., refiriéndose al reconocimiento constitucional de derechos colectivos a los pueblos indígenas. En un artículo posterior, el autor advierte que la incorporación del Convenio 169 podría implicar una discriminación a otros grupos desaventajados que también requerirían de discriminación positiva, y expondría a los miembros el grupo beneficiado a sufrir los costos de la ampliación de normas consuetudinarias, particularmente en materia penal y procesal penal, "que las reglas estatales no imponen la resto de la habitantes del país". Véase Meza-Lopehandía et al., "Desafíos y alcances de la implementación del Convenio $N^{o} 169$ de la OIT en Chile”, Anuario de Derechos Humanos, vol. 6, 2010, p. 54. El autor pasa por alto el límite que el propio Convenio impone para el reconocimiento de las instituciones indígenas: el bloque de derechos constitucionales. Tampoco se hace cargo del problema de la falta de neutralidad étnica del Estado y de la dificultad que ello supone para la realización de los miembros de las culturas minoritarias.

22. $\mathrm{Al}$ establecer que las consultas deben realizarse a través de las instituciones representativas de los pueblos interesados (art. 6.1), el Convenio confirma la dimensión colectiva del derecho de participación.

Revista de Ciencias Sociales - Número 69 (2016) - Universidad de Valparáíso - ISSN 0716-7725-Valparaíso, Chile 
características ${ }^{23}$. Por el otro lado, como necesario corolario de lo anterior, la consulta constituye un mecanismo de protección de los derechos indígenas, en un contexto de diversidad cultural que requiere de espacios especiales de diálogo para hacer visibles impactos que podrían no ser transparentes para la cultura dominante ${ }^{24}$. En este segundo sentido, la consulta previa es un procedimiento, por medio del cual se busca proteger derechos en un contexto multicultural.

\section{La consulta previa indígena ante los tribunales superiores de justicia}

A continuación presentaré una reconstrucción de la jurisprudencia nacional en materia de consulta previa indígena. El foco estará puesto en dos aspectos que buscan establecer el grado en que los tribunales han comprendido el carácter multicultural del Convenio 169, y de su "piedra angular", la consulta previa indígena, condición indispensable para su cumplimiento sustantivo.

Primero, revisaré la recepción que ha tenido la dimensión participativa de la consulta previa. Particularmente, me enfocaré en el grado en que los tribunales superiores de justicia han entendido la novedad jurídica que supone incorporar esta institución de participación multicultural al ordenamiento jurídico.

23. James Anaya, en su calidad de Relator Especial para Pueblos Indígenas de

Naciones Unidas ha elaborado los estándares que debe cumplir la consulta previa indígena. Fundamentalmente se ha referido a su carácter previo, dialógico, de buena fe (o sea, orientado a alcanzar el consentimiento indígena), llevado a cabo mediante un procedimiento acordado, adecuado, sistemático y transparente, que genere confianza entre las partes, y verificado a través de todas las instituciones representativas indígenas. En este sentido, Anaya, James: "Informe del Relator Especial sobre la situación de los derechos humanos y las libertades fundamentales de los indígenas”, 2009, A/HRC/ 12/34/Add.6. Disponible en: http://goo.gl/o9lnG6. Fecha de consulta: 25 de julio de 2016. La Corte IDH ha hecho suyo estos estándares en la sentencia del caso Sarayaku v. Ecuador (2012) (párrs. 177-211).

24. En palabras del relator Anaya, debe consultarse "siempre que una decisión del Estado pueda afectar a los pueblos indígenas en modos no percibidos por otros individuos de la sociedad”. Anaya, James, ob. cit. Párr. 43.

Facultad de Derecho y Ciencias Sociales - Universidad de Valparaíso - Chile 
El segundo aspecto que analizaré, es la medida en se ha acogido la noción de territorio indígena en la jurisprudencia, y el modo en que ha interactuado con la noción de afectación directa, en tanto requisito de procedencia de la consulta previa. De esta manera, pretendo evidenciar el grado en que los tribunales han accedido a leer conceptos jurídicos fundamentales en clave multicultural, y así hacer operativa la consulta previa.

\subsection{La consulta previa indígena como mecanismo de participación multicultural}

Como ya se ha dicho, el multiculturalismo liberal reconoce el valor de la cultura con que cada individuo se identifica, en la medida en que aquella opera como contexto que permite dar significado a las decisiones de cada uno. En este sentido, los derechos colectivos son parte del proyecto liberal, en la medida en que proveen al grupo de protecciones externas frente a las pretensiones de la sociedad dominante que pueden deteriorar dicho contexto.

La consulta previa indígena se enmarca en este programa, en tanto busca habilitar la participación colectiva para la protección de los derechos colectivos frente a dichas pretensiones. Esto explica por qué la participación contemplada en el Convenio 169, y operativizada en la CPI, consagra algo más que una simple deferencia por la opinión indígena, tal como está concebida en la Ley de Desarrollo Indígena $\mathrm{N}^{\circ} 19.253$ de 1993 (LDI ${ }^{25}$ y, en general, en la Ley $\mathrm{N}^{\circ} 19.300$ de 1996 sobre Bases Generales del Medio Ambiente ${ }^{26}$. De hecho, la consulta está concebida como un mecanismo para el diálogo intercultural, orientado a obtener, de buena fe, el consentimiento de los afectados por la medida propuesta. Es en este sentido que tiene una "diferencia esencial", con otros mecanismos de participación existentes en el ordenamiento jurídico chileno. Esto parece haber sido lo que entendió el propio Tribunal Constitucional (TC) al evaluar la constitucionalidad

\footnotetext{
25. Arts. 34 y 35 Ley N ${ }^{\circ} 19.253$ de 1993.

26. Art. 29 Ley N 19.000 de 1994.
}

Revista de Ciencias Sociales - Número 69 (2016) - Universidad de Valparáíso - ISSN 0716-7725-Valparaíso, Chile 
del Convenio. De hecho, al rechazar la tesis del Gobierno que sostenía que la consulta previa no implicaba mayores efectos jurídicos internos, pues sus disposiciones ya estaban materializadas en la institucionalidad vigente, el tribunal señaló que no la compartía, "habida consideración de la diferencia esencial que tiene la consulta [...] con aquellas otras que se establecen en el actual ordenamiento positivo. Para demostrarlo baste señalar que si bien la respuesta a la consulta a que se refiere el tratado no tiene un carácter vinculante stricto sensu si tiene una connotación jurídica especial que se encarga de precisarla el $\mathrm{N}^{\circ} 2^{\circ}$ del mismo artículo $6^{\circ}$ que dice: 'Las consultas llevadas a cabo en aplicación de este Convenio deberán efectuarse de buena fe y de una manera apropiada a las circunstancias, con la finalidad de llegar a un acuerdo o lograr el consentimiento acerca de las medidas propuestas"'27. [sic]

De esta manera, de acuerdo al TC, la diferencia decisiva entre la consulta previa indígena y los modos de participación contemplados en la legislación, es la finalidad que estructura cada procedimiento. Mientras que la participación contemplada en las leyes busca que la perspectiva indígena sea considerada en la toma de decisiones públicas, la consulta tiene la "finalidad de llegar a un acuerdo o lograr el consentimiento acerca de las medidas propuestas" 28 . Ahora bien, como la consulta previa no es un instrumento de descolonización, sino que de protección multicultural, el consentimiento solo opera como finalidad del procedimiento, y no como requisito para la adopción de decisiones públicas (derecho a veto) ${ }^{29}$.

27. Diputados de la República (2000), Requerimiento de inconstitucionalidad C ${ }^{\circ}$ 169. Rol 309: c. $7^{\circ}$.

28. Esta sentencia incurrió en una contradicción flagrante al utilizar el mismo art. 34, junto a la participación ciudadana del sistema de evaluación ambiental, para afirmar que "los procedimientos de consulta del Convenio ya se encuentran incorporados a la legislación interna” (c. $\left.70^{\circ}\right)$.

29. Diversas instancias internacionales han identificado ciertas circunstancias en que el consentimiento indígena es necesario para adoptar medidas que afecten drásticamente sus modos o condiciones de vida. En este sentido, Meza-Lopehandía, Matías, "El Convenio $\mathrm{N}^{\circ} 169$ sobre pueblos indígenas y tribales de la Organización Internacional del Trabajo". En: Aylwin, José, et. al., en "Los pueblos indígenas y el

Facultad de Derecho y Ciencias Sociales - Universidad de Valparaíso - Chile 
El segundo pronunciamiento el Convenio emitido por el TC, volvió sobre la idea "que la finalidad de las consultas es la de llegar a un acuerdo acerca de las medidas propuestas", aunque puso el énfasis en el carácter no vinculante de la negociación y la caracterizó como una "forma de recabar opinión" 30 . Esta ambigüedad entre dos entendimientos de la consulta — la consulta como procedimiento para recabar opinión y la consulta como diálogo intercultural orientado a llegar a un acuerdo- se resuelve de dos modos. Primero, teniendo presente que la sentencia citada buscaba distanciarse de un entendimiento de la consulta previa como un modo de deliberación soberana, pero no para oponerse a entenderla como un diálogo intercultural genuino, esto es, con la finalidad de llegar a un acuerdo. En segundo lugar, como destaca Fuenzalida $^{31}$, en una sentencia posterior, el TC ratificó que el Convenio consagra una consulta distinta a la prevista en la LDI, que no implica ejercicio de soberanía y que resulta compatible con la participación democrática contemplada en el texto constitucional ${ }^{32}$.

De esta manera, se reafirmó la idea contenida en la primera sentencia, esto es, que el Convenio innova al establecer que al recabar la opinión de los indígenas sobre los asuntos que les afecten, se debe buscar un acuerdo con aquellos, y no simplemente considerar sus opiniones. Esto lleva implícita la necesidad de un procedimiento adecuado, que permita llevar a cabo un diálogo (intercultural) para alcanzar el fin propuesto (el acuerdo).

derecho" Ediciones LOM, Santiago, pp. 337-439. Sin embargo, este veto emana del derecho a la supervivencia como culturas diferenciadas, y no es una manifestación de su libre determinación.

30. Cámara de Diputados (2008): Tribunal Constitucional control de constitucionalidad C ${ }^{\circ}$ 169. Rol 1050:c. $14^{\circ}$.

31. FUENZALIDA, Sergio: "Desarrollo de la Jurisprudencia en Chile sobre la Consulta Indígena: Los Casos del Tribunal Constitucional y la Corte Suprema”. En: Revue Quebecoise de Droit International, Special Edition, 2015, pp. 149-177.

32. Senadores de la República (2013): Tribunal Constitucional requerimiento de inconstitucionalidad proyecto de ley incluido en el Boletín No 8091-21. Rol 2387: c. $24^{\circ}$.

Revista de Ciencias Sociales - Número 69 (2016) - Universidad de Valparáíso - ISSN 0716-7725-Valparáiso, Chile 
Ahora bien, la discusión sobre la naturaleza de la consulta previa indígena continuó por los siguientes dos años, esta vez, ventilada ante los tribunales superiores de la justicia ordinaria. A continuación presentaré el modo en que esta cuestión se ha ido resolviendo a favor de una interpretación armónica con la idea (implícita) que la consulta previa introdujo un elemento de multiculturalismo liberal ausente anteriormente en nuestro ordenamiento jurídico.

\subsubsection{La consulta previa como una institución vacía: la doctrina "Palguin"}

El primer pronunciamiento de la Corte Suprema (CS) en materia de consulta previa indígena del que se tenga conocimiento es del 9 de septiembre de 2009, esto es, sólo unos días antes de la entrada en pleno vigor del Convenio. En esta decisión, la Corte validó una consulta llevada a cabo por el Programa Orígenes sobre una propuesta de reforma constitucional de reconocimiento de los indígenas, que, de acuerdo a los recurrentes, se habría citado bajo pretexto de informar sobre proyectos propios del programa (superación de la pobreza indígena), y en ellas se les habría entregado un formulario sobre la cuestión del reconocimiento constitucional. La Corte justificó su decisión invocando el artículo 34 de la LDI, señalando que el hecho de recabar opiniones no constituía una arbitrariedad ni vulneraba garantías constitucionales ${ }^{33}$. De esta manera, equiparó la consulta previa con la obligación de escuchar a las organizaciones indígenas contemplada en la LDI, negando en la práctica efectos al Convenio 169 de la OIT en esta materia ${ }^{34}$.

El primer desafío a este entendimiento de la consulta previa vino desde la Ilustre Corte de Apelaciones (ICA) de Temuco, en la sentencia del caso conocido como lof Palguin, relativo a la aprobación de un proyecto de piscicultura. En ésta, la Corte afirmó que el Convenio 169

33. Huilcaman con Huaracan (2009), 769-2009: c. 3. Confirmada íntegramente por la CS, rol 5940-2009. Pronunciada por ministros(as) Oyarzún, Dolmestch, Carreño, Araneda, y abogado Ruiz.

34. Cabe mencionar que la sentencia no invocó el periodo de vacancia en que se encontraba el instrumento para justificar su decisión.

Facultad de Derecho y Ciencias Sociales - Universidad de Valparaíso - Chile 
enriquecía la LDI y "perfecciona y llena de contenido al artículo 34 de dicha ley puesto que, las consultas, según el convenio deben ejecutarse de buena fe y de una manera apropiada a las circunstancias con la finalidad de llegar a un acuerdo acerca de las medidas propuestas" ${ }^{35}$. Asimismo, precisó que, siendo la Resolución de Calificación Ambiental (RCA) una medida administrativa susceptible de afectar a los recurrentes indígenas, la autoridad "debió llamar a la consulta respectiva en los términos que señala el Convenio y no a simples actos denominados de sociabilización que distan mucho en forma y contenido de lo que pretende el Convenio 169 vigente en nuestra legislación interna"36.

Pese a la concordancia de esta decisión con el derecho internacional, la CS revocó la sentencia afirmando dos cuestiones fundamentales. Primero, que la consulta previa indígena era equivalente al procedimiento de participación ciudadana contemplado en la Ley 19.300, pues éste "otorga a la comunidad interesada instancias plenas de participación" ${ }^{37}$. En segundo lugar, y como consecuencia de lo anterior, estableció que la consulta previa no procedería respecto de los proyectos que ingresen al SEIA mediante Declaración de Impacto Ambiental (DIA), en la medida en que dicho procedimiento no contemplaba participación ciudadana ${ }^{38}$. De esta manera, la Corte negó la especificidad jurídica de la consulta y agregó como requisito de procedencia la magnitud de la afectación, lo cual no es parte del estándar internacional ${ }^{39}$. Ambas cuestiones constituyen el núcleo de lo que puede

35. Puelman con COREMA Araucanía (2010), ICA Temuco, 1705-2009: c. 10².

36. Puelman con COREMA Araucanía (2010): c. $10^{\circ}$.

37. Puelman con COREMA Araucanía (2010), CS 1525-2010: c. $12^{\circ}$. Cabe recordar que la primera sentencia del TC señaló lo mismo respecto del régimen de participación ciudadana del SEIA.

38. Puelman con COREMA Araucanía (2010): c. $11^{\circ}$. Cabe tener presente que, para desechar la procedencia de un EIA, la Corte solo evaluó la causal de reasentamiento de comunidades humanas, omitiendo la localización próxima a población protegida susceptible de ser afectada, también contemplada en la Ley 19.300.

39. Meza-Lopehandía, Matías., et. al., "El derecho a la consulta y su incorporación al sistema jurídico chileno”. En: El derecho a la consulta de los pueblos indígenas:

Revista de Ciencias Sociales - Número 69 (2016) - Universidad de Valparáíso - ISSN 0716-7725-Valparaíso, Chile 
llamarse la "doctrina Palguin", la que tendrá una influencia significativa, aunque no definitiva, en las decisiones posteriores.

Poco después, la ICA de Puerto Montt realizó un nuevo desafío a la novel doctrina. En el caso Vera Millaquen (Comunidad Pepiukelen) con Pesquera Los Fiordos, se reclamaba contra la construcción de una piscina para contener aguas contaminadas en un terreno colindante con la propiedad de la comunidad, lo que afectaba sus proyectos de etnoturismo y sus actividades ceremoniales. La Corte invocó la primera sentencia del TC, y rechazó la "doctrina Palguin", sosteniendo que “ya sea una declaración o estudio de impacto ambiental, los pueblos indígenas involucrados deben ser consultados, puesto que el Convenio consagra el derecho a la participación”. Además, distinguió explícitamente entre la participación de la ley ambiental y la participación contemplada en el Convenio 169" ${ }^{40}$. La CS ratificó la sentencia de alzada, pero justificó su decisión únicamente en la vulneración del derecho a vivir en un medio ambiente libre de contaminación, eliminando los considerandos que desahuciaban la "doctrina Palguin" De esta manera, el máximo tribunal evacuó una sentencia que, al tiempo de dar protección al derecho cuya afectación era el centro del litigio, desconoció el derecho a la participación implícito en la consulta previa.

La doctrina "Palguin" tuvo una importante ratificación en el conocido caso ducto CELCO, también de $2010^{42}$. En éste, varias comunidades mapuche-lafkenche impugnaron la legalidad de la RCA

Análisis del derecho nacional, internacional y comparado, IWGIA, Temuco/Copenhague, 2014, pp. 19-45.

40. Vera Millaquen con Los Fiordos Ltda. (2010): ICA Puerto Montt, 36-2010: c. $9^{\circ}$.

41. Vera Millaquen con Los Fiordos Ltda. (2010): CS, 5757-2010. Adoptada por ministros(as) Muñoz, Carreño, Pierry, Araneda y Jacob. El Ministro Muñoz estuvo por confirmar íntegramente la sentencia y que las obras que originaba la reclamación requerían ingresar al SEIA.

42. Nahuelpan con COREMA Los Ríos (2010): CS, 4078-2010. Sentencia adoptada por ministros(as) Carreño, Pierry, Araneda, y Jacob. El ministro Brito estuvo por acoger el recurso y redactó un voto disidente al que me refiero más adelante.

Facultad de Derecho y Ciencias Sociales - Universidad de Valparaíso - Chile 
que autorizaba la construcción de un sistema de descargas industriales al mar, principalmente por falta de consulta previa indígena conforme al Convenio 169 de la OIT. En la primera instancia, la ICA de Valdivia había desechado el recurso, siguiendo la homologación de participación ciudadana y consulta indígena hecha por la CS días antes en el caso Palguin ${ }^{43}$.

En su fallo confirmatorio, la Corte Suprema siguió la misma línea del tribunal a quo, e invocó el principio de aplicación flexible del artículo 34 del Convenio, concluyendo que "el deber general de consulta a los pueblos indígenas en lo concerniente a los procedimientos de evaluación de impacto ambiental estatuido en la Ley $\mathrm{N}^{\circ} 19.300$ y su Reglamento ya se encuentra incorporado a dicha legislación ambiental a través del procedimiento de participación ciudadana que los artículos 26 a 31 de la citada ley establecen”, el cual contemplaría todas la etapas para dar por cumplida la consulta (información previa, observaciones, resolución fundada, e impugnabilidad ${ }^{44}$. Además, indicó que las instancias de información verificadas en el caso concreto, más el número de observaciones ingresadas, evidenciaban que se había cumplido con el estándar del Convenio $169^{45}$.

Ahora bien, la decisión no fue unánime. El Ministro Brito redactó un voto disidente, en que justificó la existencia de una instancia distinta de participación indígena, acorde con el Convenio 169 de la OIT, y afirmó que "[i]nformar no constituye un acto de consulta, porque cuando sólo se entregan antecedentes quien los recibe no tiene posibilidad de influir en la decisión". Comenzó a abrirse paso la especificidad normativa de la consulta del Convenio, en particular, su dimensión participatoria.

\footnotetext{
43. Nahuelpan con COREMA Los Ríos (2010): ICA Valdivia, 48-2010.

44. Nahuelpan con COREMA Los Ríos (2010): CS, 4078-2010: c. $7^{\circ}$.

45. Nahuelpan con COREMA Los Ríos (2010): c. $9^{\circ}-10^{\circ}$.
}

Revista de Ciencias Sociales - Número 69 (2016) - Universidad de Valparáíso - ISSN 0716-7725-Valparaíso, Chile 


\subsubsection{La consulta previa indígena como novedad jurídica: la doctrina "Brito"}

Esta visión disidente logró por primera vez la mayoría en el siguiente caso conocido por la Corte Suprema. Se trataba de la impugnación por falta de consulta previa de una RCA favorable a un proyecto de transferencia de residuos sólidos, que había sido ingresado al SEIA mediante DIA. Al ratificar la decisión de primera instancia ${ }^{46}$, la Corte indicó que, en la medida en que el proyecto debía entrar al SEIA por EIA, "la autoridad administrativa debió considerar el procedimiento de participación ciudadana de los artículos 26 a 31 de la Ley $\mathrm{N}^{\circ} 19.300$, contemplando además los estándares del Convenio $\mathrm{N}^{\circ} 169$ sobre Pueblos Indígenas y Tribales" ${ }^{47}$.

De esta manera, el máximo tribunal comenzó a apartarse de su idea precedente, esto es, que la participación ciudadana en el marco de la EIA equivalía a la consulta previa del 169, y siguió la tesis del ministro Brito, o sea que se trata de procesos distintos y distinguibles.

La nueva doctrina se fue abriendo paso paulatinamente. En mayo de 2011, la Corte Suprema falló en definitiva el caso del nuevo aeropuerto de la Araucanía. En éste, comunidades mapuche impugnaban la concesión de la obra emplazada en el territorio ancestral Kiñel Mapu Pulalko, afectando sitios de significación cultural y religiosa, sin consulta previa, pese a que el Convenio 169 ya estaba vigente al momento de la adjudicación del contrato. En primera instancia, la ICA de Santiago había rechazado el recurso, basándose en la homologación de participación ciudadana y consulta previa, y en que la definición del emplazamiento del aeropuerto se había hecho mucho antes que la adjudicación de la concesión, cuando el Convenio aún no era ratificado $^{48}$. Aunque la Corte Suprema confirmó el fallo, lo fundó

46. Manquepillan con COREMA Los Ríos (2010): ICA Valdivia, 243-2010.

47. Manquepillan con COREMA Los Ríos: CS, 6062-2010. Sentencia pronunciada por ministros(as) Carreño, Pierry, Araneda, Brito y Abogado Mauriz.

48. Reyes Alcaman con MOP (2011): ICA Santiago, 1794-2010: c. $4^{\circ}, 8^{\circ}, 10^{\circ}$.

Facultad de Derecho y Ciencias Sociales - Universidad de Valparaíso - Chile 
exclusivamente en la extemporaneidad, suprimiendo los considerandos en que se equiparaba consulta previa y participación ciudadana ${ }^{49}$.

Pese a la tendencia que estas decisiones comenzaban a marcar, la CS volvió a la doctrina "Palguin" en un caso en que impugnó la RCA favorable del proyecto de "Exploración Minera Catanave", ubicado en la Reserva Nacional Las Vicuñas, y territorio aimara. La Corte confirmó la sentencia de primera instancia, que había invocado la jurisprudencia del caso "ducto CELCO", al homologar la consulta previa a la participación ciudadana ambiental ${ }^{50}$.

Un mes después del revés del caso "Catanave”, en julio de 2011, la Corte Suprema tomó una decisión que a la postre marcaría un nuevo rumbo para la jurisprudencia en materia de consulta indígena. Se trata de la sentencia definitiva que resolvió el recurso interpuesto por el Consejo de Pueblos Atacameños y otros en contra de la resolución que había adoptado el nuevo "Plan Regulador San Pedro de Atacama", aprobado mediante DIA y sin consulta previa indígena.

En la sentencia de primera instancia, la ICA de Antofagasta, desechó el recurso siguiendo de cerca el precedente de Palguin ${ }^{51}$. Sin embargo, la Corte Suprema estableció que era evidente que al Plan Regulador afectaba directamente a los recurrentes, lo que incluso era reconocido por la propia resolución impugnada. Además, indicó que las instancias de participación verificadas no alcanzaban el estándar internacional, pues "desplegar información no constituye un acto de consulta a los afectados, pues éstos, en ese escenario, no tienen posibilidades reales de influir en la nueva planificación territorial del lugar donde están localizados, cuya gestación, en la especie, habría tenido en miras la protección de los derechos de esos pueblos y garantizar

49. Reyes Alcaman con MOP (2011): CS, 1608-2011. El Ministro Brito estuvo por acoger el recurso, por cuanto la resolución atacada era susceptible de afectar a los recurrentes y el Convenio estaba vigente al momento de su adopción.

50. Municipalidad de Putre con COREMA Arica y Parinacota (2011): ICA Arica, 9-2011: c. $14^{\circ}$

51. Consejo de Pueblos Atacameños con COREMA (2010): ICA Antofagasta, 7822010: c. $10^{\circ}$.

Revista de Ciencias Sociales - Número 69 (2016) - Universidad de Valparáíso - ISSN 0716-7725-Valparáiso, Chile 
el respeto de su integridad. Es decir, la autoridad administrativa recurrida aspirará a allanar las dificultades que están experimentando las comunidades indígenas atacameñas [...] prescindiendo de la participación y cooperación de éstas" 52 .

Posteriormente, la Corte Suprema dará otra señal en este sentido. Aunque confirmó la sentencia de primera instancia que desechaba un recurso de protección interpuesto contra el EIA del proyecto minero "Manganeso Los Pumas", suprimió el considerando decimocuarto, que consideraba que la normativa ambiental comprendía los fines del Convenio 169 al "establece[r] como un principio general la participación ciudadana" y al "dispone[r] eventos de participación y consulta ciudadana $[\ldots]$ antes que estos emitan pronunciamiento en un acto administrativo final" ${ }^{\text {"3 }}$.

La tendencia se afirmaría con mayor permanencia a partir de dos casos resueltos casi en forma simultánea por la Corte Suprema. Se trata de las sentencias de "Parque Eólico de Chiloé" y caso "Paguanta", que siguieron de cerca los argumentos provistos en el caso del Consejo de Pueblos Atacameños, y en general, en los votos disidentes del Ministro Brito.

En el primero de ellos, dictado casi un año después que "Palguin", la Corte Suprema dio protección a la Comunidad Antu Lafquen que reclamaba contra la DIA que autorizó el proyecto "Parque Eólico Chiloé" sin consulta previa indígena, pese a encontrarse a 4 kilómetros de la comunidad y a unos 400 metros de un cementerio indígena, lo que, de acuerdo a los recurrentes, afectaba también la vocación pesquera y turística de la zona. La CS revocó el fallo de primera instancia, que se fundaba en la doctrina "Palguin" 54 .

52. Consejo de Pueblos Atacameños con COREMA (2011): CS, 258-201: c. $8^{\circ}$.

53. Grunewald Condori con Intendente Arica y Parinacota (2011): ICA Arica, 3592011. Confirmada parcialmente por CS, rol 10.869-2011, dictada por ministros(as) Carreño, Pierry, Araneda, Brito y Sandoval.

54. Comunidad Antu Lafquen con COREMA Los Lagos (2011): ICA Puerto Montt, 239-2011.

Facultad de Derecho y Ciencias Sociales - Universidad de Valparaíso - Chile 
La sentencia caracterizó la consulta como una concreción del "del derecho esencial que la Constitución Política consagra en su artículo primero a todos los integrantes de la comunidad nacional, cual es el de intervenir con igualdad de condiciones en su mayor realización espiritual y material posible" ${ }^{25}$. Luego, la sentencia corrigió el modo de coordinación entre el SEIA y la consulta previa propuesto en la doctrina anterior, estableciendo que cuando procede el EIA, siempre debe consultarse $^{56}$. A este respecto, siguiendo el criterio esbozado anteriormente en "Estación de Transferencia", la Corte señaló que la participación ciudadana ambiental no sustituye a la consulta previa, sino que aquella "deberá ajustarse además a los términos que el Convenio $\mathrm{N}^{\circ} 169$ contempla, lo cual permitirá asegurar el derecho antes aludido" ${ }^{" 57}$.

Por otra parte, y siguiendo el precedente del caso del Consejo de Pueblos Atacameños, la Corte desechó que las reuniones de acercamiento e información con la comunidad pudieran ser consideradas como consulta previa, por no contemplar mecanismos que permitieran una incidencia real "en la implementación, ubicación y desarrollo del proyecto" ${ }^{58}$.

Días después, la misma Corte resolvía en términos análogos un caso en el que se impugnaba la RCA que autorizaba mediante DIA y sin consulta previa, el Proyecto "Sondaje Prospección Paguanta", situado al interior del Área de Desarrollo Indígena (ADI) "Jiwasa Oraje"59. Asimismo, señaló que las reuniones de socialización del proyecto llevadas a cabo por la empresa no constituían consulta previa, siendo

55. Comunidad Antu Lafquen con COREMA Los Lagos (2012): CS, 10.090-

2011: c. $5^{\circ}$. Pronunciada por ministros(as) Muñoz, Pierry, Sandoval, Escobar y abogado Bates.

56. Comunidad Antu Lafquen con COREMA Los Lagos (2012): c. $7^{\circ}$.

57. Comunidad Antu Lafquen con COREMA Los Lagos (2012): c. 10.

58. Comunidad Antu Lafquen con COREMA Los Lagos (2012): c. $8^{\circ}$.

59. Consejero Territorial Alto Tarapacá con Directora SEA Tarapacá (2012): CS, 11.040-2011:c. 6-8 ${ }^{\circ}$. Revocando sentencia ICA Iquique, rol 472-2011. Dictada por ministros(as) Muñoz, Pierry, Sandoval, Escobar, y abogado Bates.

Revista de Ciencias Sociales - Número 69 (2016) - Universidad de Valparáíso - ISSN 0716-7725-Valparáiso, Chile 
otra vez determinante las posibilidades de incidencia en la decisión final ${ }^{60}$. Al igual que en "Parque Eólico", la Corte exigió el ajuste del procedimiento de participación ciudadana a los estándares del Convenio 169, estableciéndose que el proceso de consulta debía llevarse a cabo en el marco del SEIA, pero adoptando los estándares internacionales ${ }^{61}$.

En abril de 2012, la Corte Suprema confirmó la sentencia de la ICA de Antofagasta en el caso "El Morro (I)", referido a un proyecto minero de enormes proporciones, emplazado al interior de las tierras inscritas de la comunidad de los diaguitas huascoaltinos, el que contemplaba un relave ubicado en una de las quebradas que surte de agua al valle del Huasco ${ }^{62}$.

La sentencia confirmada recordó que el Convenio reconoce a los pueblos indígenas el derecho a decidir sus propias prioridades de desarrollo y a participar en la utilización, administración y conservación de los recursos naturales presentes en sus territorios, por lo que el proyecto debía ser consultado, "para determinar si los intereses de estos pueblos son perjudicados y en qué medida, antes de emprender o autorizar cualquier programa de prospección o explotación podrían dañarse” ${ }^{63}$. Asimismo, señaló que las reuniones no habían sido específicamente indígenas, y que por lo tanto se requería una "audiencia específica en cuanto a sus necesidades" ${ }^{4}$.

60. Consejero Territorial Alto Tarapacá con Directora SEA Tarapacá (2012): c. $9^{\circ}$.

61. Consejero Territorial Alto Tarapacá con Directora SEA Tarapacá (2012): c. $11^{\circ}$.

62. Comunidad Agrícola Los HuascoAltinos con COREMA Atacama (2012): CS, 2211-2012. Confirmando rol 618-2011.

63. ICA Antofagasta, 618-2011: c. $10^{\circ}$.

64. ICA Antofagasta: c. 9-10 ${ }^{\circ}$. Cabe destacar que la Corte consideró insuficientes la compensación y mitigación los acuerdos alcanzados con tres familias de crianceros pertenecientes a la Comunidad, excluyendo al resto de los integrantes de ésta. Además, consideró irrelevante que los recurrentes estuvieran constituidos como Comunidad Agrícola y no como Comunidad Indígena. Con ello, el máximo tribunal reconoció la dimensión colectiva de los derechos territoriales reclamados, y la auto identificación como criterio fundamental de etnicidad.

Facultad de Derecho y Ciencias Sociales - Universidad de Valparaíso - Chile 
La jurisprudencia del multiculturalismo en Chile...

\subsubsection{Caso Pokura y los Tribunales Ambientales: ¿La restauración de la doctrina "Palguin"?}

Dos años después de la sentencia del caso "El Morro (I)", la vigencia de la nueva doctrina comenzó a debilitarse. En el caso "Pokura", los comuneros mapuche de ese lugar recurrieron de protección ante la ICA de Valdivia por la falta de consulta previa respecto de la instalación de un sistema de agua potable rural en su territorio, el cual incluía obras de captación y de redes de distribución, que modificarían las condiciones del terreno y cercas, y provocarían el reblandecimiento del terreno en sectores de alta pendiente. En aplicación de la jurisprudencia vigente, la ICA de Valdivia acogió el recurso, ordenando al MOP adecuar el proceso de consulta al procedimiento de consulta contenido en el DS 66 del Ministerio de Desarrollo Social. Al remitir a dicho procedimiento, el tribunal lo consideró implícitamente como adecuado al estándar internacional de consulta previa indígena ${ }^{65}$.

En forma sorpresiva, la Corte Suprema revocó la sentencia de alzada, argumentando que el reglamento citado no estaba vigente a la fecha de los hechos denunciados, y que por lo mismo no podía ser aplicado $^{66}$. Ahora bien, la Corte no se hizo cargo del hecho de que la consulta efectuada conforme al DS $\mathrm{N}^{\circ} 124$ de 2009 no respondía a los estándares que anteriormente ella misma había establecido, pues éste había consistido en una mera entrega de información del proyecto, y no en un proceso de consulta ${ }^{67}$.

La incertidumbre generada por esta decisión se ha agudizado con la entrada en vigor de los Tribunales Ambientales (TA ${ }^{68}$. Estos tienen competencia para conocer la reclamación contra las resoluciones de calificación ambiental una vez agotada la vía administrativa ${ }^{69}$, lo

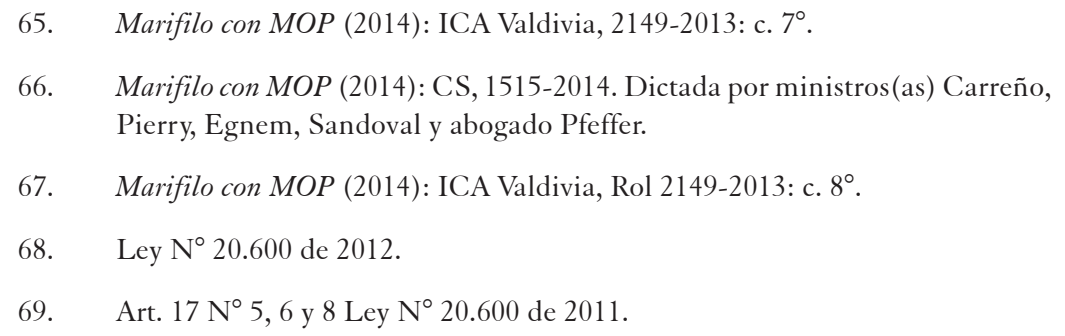


que ha permitido que los tribunales superiores se excusen de conocer el fondo de las cuestiones sometidas a su conocimiento, invocando la competencia de dichos tribunales ${ }^{70}$. Ahora bien, en el caso conocido como "El Morro IV", la Corte estableció lo que podría haberse constituido como un precedente significativo, al señalar que estas pretensiones debían resolverse en la nueva institucionalidad ambiental "salvo que se vislumbre la necesidad de adoptar alguna medida cautelar de carácter urgente" ${ }^{71}$. Sin embargo, recientemente la Corte ha renunciado a pronunciarse en el caso de la aprobación de la Central Hidroeléctrica Añihuerraqui, que inunda territorio mapuche, incluyendo sitios ceremoniales, por estar pendiente su resolución ante los TA, aun cuando la obra podría afectar derechos constitucionalmente garantizados $^{72}$. Está por verse el modo en que los nuevos tribunales entenderán los derechos consagrado en el Convenio 169 y en particular, la consulta previa.

\subsection{La afectación directa y las dimensiones de lo multicultural}

El artículo $6^{\circ}$ del Convenio 169 entrega los elementos básicos de la consulta previa. Señala que los pueblos indígenas deben ser consultados respecto de todas las "medidas legislativas o administrativas susceptibles de afectarles directamente". Establece así dos determinantes de la consulta previa: (i) la susceptibilidad de afectación; y (ii) la proximidad de afectación. Esta última, que se refiere a la proximidad causal y no a una proximidad geográfica, limita la procedencia de la consulta, siendo su determinación, necesariamente, casuística ${ }^{73}$. Sin

70. La cuestión de los TA fue planteada por primera vez por la CS en el Rol 16.817-2013, aunque esta no eludió el fondo del asunto. Poco después, el máximo tribunal revocó una sentencia favorable a las pretensiones de los recurrentes, aduciendo la competencia de los TA (Rol 17.120-2013; también roles 22.461-2014 y 10.349-2015).

71. Comunidad Diaguita Yastai de Junta de Valeriano con Comisión de Evaluación Ambiental (2014): CS, 11.299-2014: c. $9^{\circ}$.

72. Lof Trankura con CEA (2015): CS, 33.154-2015, confirmando rol 3956-2015.

73. Además del carácter no remoto de la afectación, Contesse enfatiza su especificidad. En: Contesse, Jorge: "El derecho de consulta previa en el Convenio 169

Facultad de Derecho y Ciencias Sociales - Universidad de Valparaíso - Chile 
perjuicio del interés práctico que esto puede suscitar, fijaremos nuestra atención en la primera cuestión, esto es, en la susceptibilidad de la afectación, en la medida en que el modo en que ha sido entendida y aplicada por los tribunales superiores de justicia indica el grado en que el Convenio, en tanto instrumento del multiculturalismo, ha permeado el ordenamiento jurídico, en particular a los jueces. Esto por dos motivos. Lo primero es que el Convenio no se exige certeza en la afectación, justamente porque en un contexto de diversidad, es la eventual opacidad de las valoraciones ajenas lo que exige mecanismos especiales de comunicación intercultural ${ }^{74}$. Por esto, la ICA de Temuco señaló certeramente que "no se trata de un verbo [susceptibles de afectar] que señale que para que la consulta proceda deben verse afectados inmediatamente por la medida sino que sean susceptibles de afectarles directamente" $[\mathrm{sic}]^{75}$.

La segunda cuestión significativa es la afectación entendida en su dimensión cultural, es decir, el modo en que el concepto de afectación se diversifica y amplía al adoptar la perspectiva del multiculturalismo liberal. Un indicador relevante en este punto es el grado en que la noción de hábitat indígena ha permeado el concepto legal de tierra indígena. Como ya se ha dicho, el Convenio protege la relación, identitariamente

de la OIT. Notas para su implementación en Chile", Ediciones Universidad Diego Portales, Santiago, 2010. Esto último no debe confundirse con exclusividad de la afectación. Tal como ha señalado el relator Anaya, "la consulta se aplica incluso con respecto a medidas administrativas o legislativas de aplicación general, por ejemplo, con respecto a un nueva ley de pesca o de fomento forestal, cuando dichas medidas de algún modo afecten de manera diferenciada a los pueblos indígenas”. Citado en MezaLopehandía et al., ob. cit., p. 30.

74. En este sentido, si la autoridad pretende negarse a consultar cuando esto es requerido por un pueblo indígena que alega una eventual afectación, tiene un deber reforzado de fundamentación, pues tiene que remontar dicha opacidad. Esto es especialmente difícil, pues la autoridad requerirá apoyarse en especialistas (peritajes antropológicos), formados en instituciones no indígenas, que deben determinar cuál es la verdadera cultura de quienes reclaman la consulta. El hálito colonialista de esta situación es evidente.

75. Puelman con COREMA Araucanía (2010): ICA Temuco, 1705-2009: c. $9^{\circ}$.

Revista de Ciencias Sociales - Número 69 (2016) - Universidad de Valparáíso - ISSN 0716-7725-Valparaíso, Chile 
constitutiva, que los pueblos indígenas mantienen con sus tierras y territorios, aun cuando no estén exclusivamente ocupadas por ellos, incluyendo la relación espiritual que tengan con aquellas ${ }^{76}$. De esta manera, la medida en que dicha apertura se haya logrado, incide directamente en la procedencia de la consulta, pues la susceptibilidad de afectación debe evaluarse a partir de este entendimiento ampliado de tierra indígena.

\subsubsection{Susceptibilidad de afectación y hábitat indígena}

La cuestión del hábitat indígena tuvo su primer impacto en la jurisprudencia de la Corte Suprema en el ámbito de los derechos de aguas, particularmente en el caso Chusmiza. En éste, la Corte ratificó la sentencia de alzada, confirmando que el concepto de "terrenos de la comunidad" del artículo 64 de la LDI incluía las tierras utilizadas ancestralmente por los pueblos indígenas, aun cuando fueren de dominio ajeno. Para hacer esta afirmación, se apoyó en los artículos 13, 15 y 16 del Convenio $169^{77}$.

Sin embargo, esta doctrina no irradió inmediatamente la jurisprudencia en materia de consulta previa, donde los tribunales se han mostrado menos abiertos a comprender la relación especial que une a los indígenas con sus territorios.

En el primer año de vigencia plena del Convenio, en el ya citado caso "Palguin", la ICA de Temuco demostró su comprensión del estándar internacional, poniendo el énfasis en la susceptibilidad de la afectación, pero también en el hecho de que el proyecto estaba situado en el "sector" donde habitaban los afectados: "Ahora bien, en este caso [...] existe un fundamento plausible que producto de la instalación de la piscicultura sus derechos constitucionales se vean amenazados y su costumbre y su vida diaria son susceptibles de ser afectados directamente; ya que viven en el sector donde se pretende realizar el proyecto"78.

76. Art. 13.1 y $14.1 \mathrm{C}^{\circ} 169$.

77. Papic con Comunidad Chusmiza Usmagama (2009): CS, 2840-2008.

78. Puelman con COREMA Araucanía (2010): ICA Temuco, 1705-2009: c. $9^{\circ}$.

Facultad de Derecho y Ciencias Sociales - Universidad de Valparaíso - Chile 
En otras palabras, la Corte sostuvo que la cercanía de un proyecto o su ubicación en el hábitat indígena, es criterio suficiente para que la consulta previa sea necesaria. Sin embargo, como se mencionó supra, la Corte Suprema revocó esta sentencia, generando un duradero precedente en sentido contrario ${ }^{79}$.

También en el ya revisado caso Pepiukelen, la Corte de primera instancia hizo una aplicación multicultural del Convenio ${ }^{80}$. Los recurrentes reclamaban por la construcción de una piscina para contener aguas contaminadas en un terreno vecino, de propiedad de un particular no indígena, y por lo tanto, tierra no indígena de conformidad a la LDI. La claridad del razonamiento de la Corte de alzada merece ser reproducida in extenso:

"[S]i bien los recurrentes son vecinos a la tierra indígena en que se realiza la obra de drenaje y contención de aguas, el concepto de tierras indígenas es hoy, por aplicación del artículo $13 \mathrm{~N}^{\circ} 2$ del Convenio 169, más amplio que el establecido en los artículos 12 y 13 de la Ley 19.252, y comprende además la totalidad del hábitat de las regiones que los pueblos interesados ocupan o utilizan de alguna u otra manera, en este caso en el predio deslíndante, de las comunidades recurrentes se ejecutan actividades de "Etnoturismo" y "Fiesta Costumbrista Mapuche". En consecuencia, no sólo podemos considerar el lugar que está siendo intervenido por la empresa como tierra indígena, porque así ha sido reconocido y certificado por la Corporación Nacional de Derecho Indígena, sino porque del mérito de autos aparece que dicho terreno forma parte del hábitat de una comunidad indígena" ${ }^{81}$.

Como se señaló supra, aunque la Corte Suprema ratificó esta sentencia, eliminó este considerando de la sentencia definitiva ${ }^{82}$. Algo similar sucedió en la sentencia definitiva del ya citado caso "Estación de Transferencia”, donde en primera instancia se consideró la vincu-

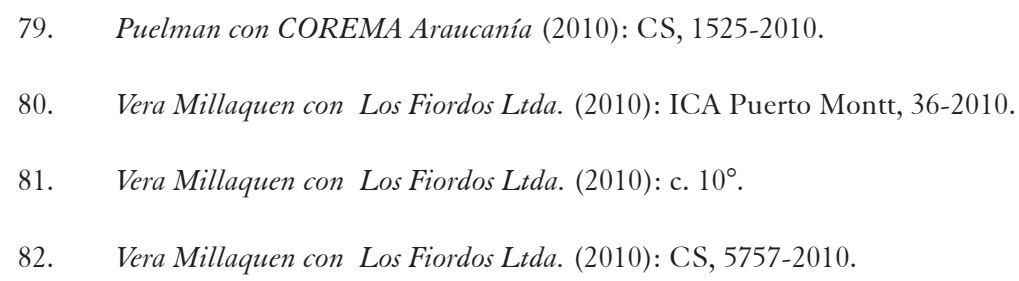


lación especial de las comunidades con el medio ambiente, y el derecho a mantenerla y fortalecerla; sin embargo, la sentencia confirmatoria eliminó los considerandos que profundizaban en el alcance de la afectación directa desde un punto de vista territorial, centrándose exclusivamente en la idea de "riesgo para la salud" de la legislación ambiental $^{83}$.

Alejándose del concepto de territorio indígena, el máximo tribunal confirmó la sentencia de la ICA de Temuco ${ }^{84}$, que había validado una RCA que autorizaba una línea de transmisión (LoncocheVillarrica) sin haber sido sometida a consulta previa ${ }^{85}$, pese a que pasaba a muy cerca de sitios ceremoniales de las comunidades del sector ${ }^{86}$. Hizo esto indicando que los recurrentes no habrían explicado de qué manera la resolución recurrida podía afectar los derechos constitucionales invocados, ni el modo en que el proyecto aprobado afectaría dichos sitios. Además, señaló que los goces existentes a menos de 100 metros del proyecto no constituirían viviendas, por lo que no se podría considerar afectados asentamientos humanos, desechando así, cualquier efecto normativo al concepto de hábitat ${ }^{87}$.

Esta resistencia del máximo tribunal a incorporar los estándares del Convenio a la determinación del criterio de afectación se elevó a un rechazo casi explícito con la sentencia definitiva del caso Manquepillan con COREMA, de junio de 2012. En primera instancia, la ICA de Temuco había concedido el recurso, basándose en que el sistema de transmisión eléctrica Melipeuco-Freire cuya autorización se impugnaba, contemplaba la instalación de postes que atravesaban terrenos de las

83. Manquepillan con COREMA Los Ríos (2011): CS, 6062-2010.

84. Comunidad Felipe Nitrihuala con COREMA Araucanía (2011): ICA Temuco, 150-2011.

85. Comunidad Felipe Nitrihuala con COREMA Araucanía (2011): CS, 4289-2011.

86. Específicamente, el menoko (1.300 mts), el lahuentuhue (500 mts) y el nguillatuhe (600 mts).

87. Comunidad Felipe Nitrihuala con COREMA Araucanía (2011): ICA Temuco, 150-2011: c. $14^{\circ}$.

Facultad de Derecho y Ciencias Sociales - Universidad de Valparaíso - Chile 
comunidades recurrentes, y que en las proximidades existían sitios de valor ritual para los mapuche ${ }^{88}$. La Corte revocó la decisión, aduciendo que el área de influencia del proyecto correspondía al ancho de la franja de seguridad de la línea eléctrica, eliminando la hipótesis de afectación sobre la base de que dicha franja era de propiedad estatal, por los que no se trataba de tierra indígena ${ }^{89}$. Además, la Corte afirmó que la cercanía física no era criterio suficiente para forzar el EIA ni la consulta, aun cuando se había acreditado la existencia de siete sitios de significación cultural en el entorno del proyecto ${ }^{90}$, argumentando que los recurrentes "no habían justificado alguna afectación a sus derechos en sus tierras, sistemas de vida, creencias y bienestar", reforzando la idea de que la cercanía por sí sola no obliga a la consulta ${ }^{91}$.

Tal como señala Carrasco, este breve fallo vuelve a la doctrina Palguin, esto es, la necesidad de que la afectación tenga una cierta "significancia”, la cual debe ser "explicitado razonablemente", trasladando así la carga de la prueba al recurrente ${ }^{92}$. Más aún, la Corte consideró como una evidencia de no afectación, el hecho que el sitio ceremonial cercano era colindante con un camino público donde ya existían postes de distribución, por lo que "no se producirá un cambio relevante en la situación actual" ${ }^{93}$. Al igual que en el caso de la

88. Asociación Tragun Mapu Maile Allipen CEA la Araucanía (2012): ICA Temuco, 349-2011.

89. Asociación Tragun Mapu Maile Allipen CEA la Araucanía (2012): CS, 16022012. En el citado caso El Morro (I), la Corte estableció como distintivo indisputable de afectación, el hecho de ser titulares de derecho de dominio inscrito sobre las tierras en que se emplazaba el proyecto.

90. Asociación Tragun Mapu Maile Allipen CEA la Araucanía (2012): c. $6^{\circ}$ y $9^{\circ}$.

91. Asociación Tragun Mapu Maile Allipen CEA la Araucanía (2012): c. $7^{\circ}$.

92. CARRASCO, Edesio: "Razonabilidad y Proporcionalidad: Criterios para la determinación de la consulta indígena en proyectos de inversión en el marco del Convenio No 169 de la OIT", Revista Chilena de Derecho, vol. 40 N 1, 2013, p. 308.

93. Asociación Tragun Mapu Maile Allipen CEA la Araucanía (2012): c. $6^{\circ}$.

Revista de Ciencias Sociales - Número 69 (2016) - Universidad de Valparáíso - ISSN 0716-7725-Valparaíso, Chile 
transmisión Loncoche-Villarrica, invocó el carácter intervenido del territorio, para desechar la afectación, lo cual resulta, al menos, desconcertante ${ }^{94}$.

Esta línea jurisprudencial ha guiado las decisiones relativas a los reclamos por otorgamiento de concesiones de exploración geotérmica sin consulta previa. En éstas, el máximo tribunal ha sostenido que no procede la consulta previa, pues la mera exploración no permitiría determinar eventuales perjuicios, sin perjuicio de lo que corresponda en la etapa de explotación ${ }^{95}$. Esta solución obvia la obligación de consultar "antes de emprender o autorizar cualquier programa de prospección” de recursos del subsuelo establecida en el Convenio (art. 15.2), y que la concesión de exploración geotérmica otorga un derecho real a su titular, independiente del domino del predio superficial, y concede derechos consuntivos sobre las aguas subterráneas, alternado así los derechos sobre el subsuelo ${ }^{96}$. Además, desconoce la posibilidad de que la exploración misma altere aspectos no visibles de la relación de los pueblos afectados con su territorio, reflejando así la incomprensión del alcance de la noción de hábitat, por un lado, y de la noción multicultural de afectación, por el otro.

Será recién en la segunda mitad del año 2013, cuando la Corte Suprema comenzará a abrirse a la nueva concepción ampliada de tierra indígena, aunque otra vez, fuera del marco del marco de la consulta previa indígena. Se trata del caso "Cementerio Topáter". En éste, una empresa inmobiliaria estaba realizando trabajos de movimiento de tierras y construcción en un sitio (urbano) aledaño al Cementerio

94. Adicionalmente, la Corte cuestionó indirectamente la importancia del impacto al aludir a que los recurrentes solo serían "seis de las casi treinta comunidades indígenas a las que el propio recurso alude” (1602-2012: c. $\left.7^{\circ}\right)$.

95. Comunidad Manquilef Hueche con Ministerio de Energía (2012): ICA Santiago, 12.652-2012: c. $9^{\circ}$. Confirmada por CS, rol 495-2013. En idéntico sentido, Cruz con Ministerio de Energía (2012): ICA Santiago, 12.533-2012, confirmada en rol 9527-2012 y Comunidad Huenchullan con Ministerio de Energía (2012): ICA Santiago, 9431-2012, confirmada en 9526-2012.

96. Artículo 5 y 27 Ley No 19.657.

Facultad de Derecho y Ciencias Sociales - Universidad de Valparaíso - Chile 
Indígena prehispánico Topáter, el cual es usado habitualmente por las comunidades licanantai de Calama para sus prácticas ancestrales de culto. Los recurrentes alegaban que la remoción de tierras no respetaría sus propias concepciones y creencias, y la vinculación espiritual del sitio con los cerros aledaños, los que conformarían un continuo antropológico. El sitio era de propiedad de la inmobiliaria, pero los recurrentes reclamaron la violación de su derecho de propiedad, entendido como derecho al acceso a tierras que ocupan de alguna manera (art. 13 Convenio 169). En la primera instancia, la ICA de Antofagasta rechazó el recurso, fundándose en que el ejecutor del proyecto estaría respetando la franja de protección del cementerio, establecida en la RCA que autorizó el proyecto "seccional Topáter" en $2004^{97}$.

En la sentencia definitiva, la Corte consideró que las actividades denunciadas afectan, no sólo el cementerio propiamente tal, cuyo valor "parece natural a la especie humana, de un valor superior e incluso sagrado" ${ }^{98}$, sino también el Cerro Fundición, que se encuentra a 250 metros del cementerio, y cuyas terrazas miran al cementerio, el cual, según los recurrentes, "no puede entenderse sin la íntima conexión existente con el denominado "Cerro Fundición"”'99. La Corte consideró perturbadas las garantías de libertad de culto e igualdad y no discriminación ${ }^{100}$.

Otra muestra de esta comprensión amplia de territorio indígena, que incluye la relación que los pueblos indígenas guardan con los elementos presentes en aquel, se encuentra en la sentencia de primera instancia del caso de la minera "Manganeso Los Pumas (II)". En éste, la ICA de Arica invocó la cosmovisión andina para configurar la afectación directa: "Que la cultura de los pueblos indígenas corresponde

97. Troncoso y Mamani con Villa Nueva S.A. (2013): ICA Antofagasta, 1414-2012.

98. Troncoso y Mamani con Villa Nueva S.A. (2013): CS, 3010-2013: c. 11.

99. Troncoso y Mamani con Villa Nueva S.A. (2013): c. $9^{\circ}$. La descripción detallada del sitio ceremonial está en la sentencia de primera instancia (ICA Antofagasta, 1414-2012: p. 15s).

100. Troncoso y Mamani con Villa Nueva S.A. (2013): c. $11^{\circ}$.

Revista de Ciencias Sociales - Número 69 (2016) - Universidad de Valparáíso - ISSN 0716-7725-Valparaíso, Chile 
a una forma de vida particular de ser, ver y actuar en el mundo, constituido a partir de su estrecha relación con sus tierras tradicionales y recursos naturales, no sólo por ser estos sus principal medio de subsistencia, sino además, porque constituyen un elemento integrante de su cosmovisión, religiosidad y por ende su identidad cultural, de todo lo cual se desprende que la probable afectación de la vertiente de la quebrada de Tarapacá lo cual al erigirse como un lugar conectado con la divinidad andina, dada la cosmovisión aymara, en que el agua se estrecha con la vida, considerada una entidad sagrada 'uma', cualquier afectación, por mínima que sea, se ve amenazada la garantía constitucional del artículo $19 \mathrm{n}^{\circ} 6$ de la Constitución Política de la República, esto es, el ejercicio libre de todo culto" ${ }^{101}$.

Como se mencionó anteriormente, la Corte Suprema revocó esta sentencia, remitiendo el asunto a los $\mathrm{TA}^{102}$.

Un poco antes de esta decisión, la Corte había propuesto un estándar de afectación, que se produciría "cuando se ven modificadas sus vidas, creencias, instituciones y bienestar espiritual, las tierras que ocupan o utilizan de alguna manera, y la posibilidad de controlar, en la medida de lo posible, su propio desarrollo económico, social y cultural" 103 . Aunque la Corte se funda en el artículo $7^{\circ}$ referido al derecho a decidir sus propias prioridades de desarrollo, los criterios invocados son suficientemente amplios para aplicarlos a la determinación de la afectación directa. El problema es que el máximo tribunal olvidó que la consulta procede cuando dicha afectación es posible, y no cuando es un hecho probado, como lo entendió en el caso citado, y también en uno posterior ${ }^{104}$, en que la CS, conociendo la casación de una sentencia dictada por un TA, ratificó esta última, que había desestimado la opinión de CONADI en orden a consultar a un conjunto de comunidades

101. Vargas con SEA Arica y Parinacota (2013): ICA Arica, 182-2013: c. $39^{\circ}$.

102. Vargas con SEA Arica y Parinacota (2013), CS, 17.120-2013.

103. Pueblos Indígenas Unidos de la Cuenca de Tarapacá con SEA (2016): CS, 8172016: c. $13^{\circ}$.

104. Pueblos Indígenas Unidos de la Cuenca de Tarapacá con SEA (2016): c. 14. 
susceptibles de ser afectadas, por cuanto "formuló sus planteamientos en términos de posibilidad y no de certeza" ${ }^{105}$.

\section{Conclusión}

He argumentado que el Convenio 169 de la OIT es un instrumento inspirado en el multiculturalismo liberal. Por lo mismo, se funda en la revalorización de la diversidad cultural, y su consecuente protección. Esto permite entender la doble función que juega la consulta previa en el entramado de dicho instrumento, esto es, que constituye un mecanismo para la participación colectiva indígena orientado a la protección de los intereses y derechos colectivos de dichos pueblos.

La adopción por parte de Chile de este instrumento, implica por tanto, una significativa innovación en el ordenamiento jurídico. Por una parte, supone la incorporación de una nueva forma de participación (la consulta), organizada como un diálogo intercultural orientado a alcanzar el consentimiento frente a las medidas propuestas. No se trata ya simplemente de escuchar y considerar a los potenciales afectados, sino que de comprometerse en una negociación de buena fe para llegar a un acuerdo, de manera de hacer visible potenciales impactos, y actuar en consecuencia. Por otra parte, el Convenio exige la resignificación, desde la diversidad cultural, de conceptos jurídicos fundamentales, tales como los de propiedad y afectación.

La jurisprudencia revisada muestra la resistencia inicial a aceptar la dimensión participativa específica de la consulta previa indígena, y el papel decisivo que ha tenido la determinación de un ministro en particular en su posterior recepción. Sin embargo, dicho avance ha sufrido retrocesos, y hoy está en un compás de espera, con la inauguración de la jurisdicción ambiental en Chile. Algo más receptivos se han mostrado los tribunales a la incorporación de la noción de hábitat indígena, aunque con vacilaciones y especiales dificultades cuando dicho concepto actúa como determinante de la procedencia de la consulta previa indígena.

105. Pueblos Indígenas Unidos de la Cuenca de Tarapacá con SEA (2015). $2^{\circ}$ TA, 542014: c. $40^{\circ}$. Confirmada por CS, rol 817-2016.

Revista de Ciencias Sociales - Número 69 (2016) - Universidad de Valparáíso - ISSN 0716-7725-Valparaíso, Chile 
El rumbo que adopten en esta materia los Tribunales Ambientales, y en general la judicatura chilena, dependerá del modo en que aquellos entiendan la opción que ha hecho el Estado de Chile al ratificar el Convenio 169 de la OIT. Este trabajo pretende ser una modesta contribución a evidenciar su carácter multicultural y liberal, y el modo en que esto determina, o debe determinar, su alcance.

\section{BIBLIOGRAFÍA CITADA}

ANAYA, James (2000): IndigenousPeoples in International Law (Nueva York, Oxford UniversityPress).

ANAYA, James (2009a): "Informe del Relator Especial sobre la situación de los derechos humanos y las libertades fundamentales de los indígenas". A/HRC/12/34/Add.6. Disponible en: http://goo.gl/o9lnG6. Fecha de consulta: 25 de julio de 2016.

ANAYA, James (2009b): "Promoción y protección de todos los derechos humanos, civiles, políticos, económicos, sociales y culturales, incluido el derecho al desarrollo". A/HRC/12/34. Disponible en: http:/ /goo.gl/le2KBU. Fecha de consulta: 25 de julio de 2016.

ANGHIE, Anthony (2007). Imperialism, Sovereignty and theMaking of International Law. (Cambridge, Cambridge University Press).

CARRASCO, Edesio (2013): "Razonabilidad y Proporcionalidad/: Criterios para la determinación de la consulta indígena en proyectos de inversión en el marco del Convenio N ${ }^{\circ} 169$ de la OIT", Revista Chilena de Derecho, vol. $40 \mathrm{~N}^{\circ}$ 1: pp. 299-314.

CONTESSE, Jorge (2012): "El derecho de consulta previa en el Convenio 169 de la OIT. Notas para su implementación en Chile".

En: Contesse, Jorge. (edit.). El Convenio 169 de la OIT y el derecho chileno. (Santiago, Ediciones Universidad Diego Portales).

FUENZALIDA, Sergio (2015): "Desarrollo de la Jurisprudencia en Chile sobre la Consulta Indígena: Los Casos del Tribunal Constitucional y la Corte Suprema”, Revue Quebecoise de Droit International, Special Ed: pp. 149-177.

Berlin Conference (1909). General Act of the Conference of Berlin Concerningthe Congo.The American Journal of International Law, vol. $3 \mathrm{~N}^{\circ}$ 1: pp. 7-25.

Facultad de Derecho y Ciencias Sociales - Universidad de Valparaíso - Chile 
La jurisprudencia del multiculturalismo en Chile...

KYMLICKA, Will (1996): Ciudadanía multicultural: una teoría liberal de los derechos de las minorías. (Madrid, Paidós).

MEZA-LOPEHANDÍA, Matías (2013a): “El Convenio Nº 169 sobre pueblos indígenas y tribales de la Organización Internacional del Trabajo”. En: Aylwin, José, Meza-Lopehandía, Matías., y Yáñez, Nancy, Los pueblos indígenas y el derecho (Santiago, LOM): pp. 337-439.

MEZA-LOPEHANDÍA, Matías (2013b) "El Derecho Internacional de los Derechos Humanos y los pueblos indígenas". En: Aylwin,

José, Meza-Lopehandía, Matías, y Yáñez, Nancy, Los pueblos indígenas y el derecho (Santiago, LOM): pp. 441-521.

MEZA-LOPEHANDÍA, Matías., SIERRA, Lucas., RIBERA, Teodoro y SALAZAR CALLASAYA, Francisca (2010): "Desafíos y alcances de la implementación del Convenio No 169 de la OIT en Chile", Anuario de Derechos Humanos, vol. 6: pp. 49-67.

MEZA-LOPEHANDÍA, Matías., YÁÑEZ, Nancy y SILVA, Hernando (2014): "El derecho a la consulta y su incorporación al sistema jurídico chileno". En: El derecho a la consulta de los pueblos indígenas: Análisis del derecho nacional, internacional y comparado. (Temuco/ Copenhague, IWGIA) pp. 19-45.

NIEZEN, Ronald (2003). The Origins of Indigenism. Human rights and thepolitics of identity. (Berkley/London,University of California Press).

NOGUEIRA, Héctor (2000). "Las constituciones y los tratados en materia de derechos humanos: América Latina y Chile", Ius et Praxis, vol. $6 \mathrm{~N}^{\circ}$ 2: pp. 227-279.

PEÑA, Carlos (2000): "Democracia y minorías", Pensamiento Constitucional, vol. $7 \mathrm{~N}^{\circ}$ 7: pp. 387-417. Disponible en: http://goo.gl/ YDT3fV. Fecha de consulta: 15 de enero de 2016.

SIERRA, Lucas (2003): "La Constitución y los indígenas en Chile: Reconocimiento individual y no colectivo”, Estudios Públicos, vol. 92: pp. 19-27.

SILVA, Alejandro (1997): Tratado de Derecho Constitucional. Tomo IV. (Santiago, Editorial Jurídica de Chile).

TAYLOR, Charles (1993): El multiculturalismo y "La política del reconocimiento": ensayo. (México, Fondo de Cultura Económica).

Revista de Ciencias Sociales - Número 69 (2016) - Universidad de Valparáíso - ISSN 0716-7725-Valparaíso, Chile 
VILLAVICENCIO, Luis (2010): La relevancia moral de la identidad cultural, Polis (Santiago), vol. $9 \mathrm{~N}^{\circ}$ 26: pp. 339-420.

VILLAVICENCIO, Luis (2012): "Un diálogo intercultural más allá del multiculturalismo", Revista Opinión Jurídica, vol. 11 No 22: pp. 31-44.

\section{NORMAS CITADAS}

Ley $\mathrm{N}^{\circ} 19.253$ (05/10/1993). Establece normas sobre protección, fomento y desarrollo de los indígenas y crea la Corporación Nacional de Desarrollo Indígena.

Ley $\mathrm{N}^{o} 19.300$ (09/03/1994). Aprueba ley sobre bases generales del medio ambiente.

Ley $\mathrm{N}^{\circ} 19.657$ (07/01/2000). Sobre concesiones de energía geotérmica. Ley No 20.600 (28/06/2012). Crea los Tribunales Ambientales.

Decreto $N^{\circ} 236$ (14/10/2008). Promulga el Convenio $\mathrm{N}^{\circ} 169$ sobre pueblos indígenas y tribales en países independientes de la Organización Internacional del Trabajo.

\section{JURISPRUDENCIA CITADA}

Corte Interamericana de Derechos Humanos.

Comunidad Mayagna (Sumo) Awas Tingni Vs. Nicaragua (2001), (Fondo, Reparaciones y Costas), Sentencia de 31 de agosto de 2001, Serie C No 79. Disponible en: http://goo.gl/WwfZTV Fecha de consulta 31 de mayo de 2016.

Comunidad indígena Yakye Axa Vs. Paraguay (2005), (Fondo, Reparaciones y Costas), Sentencia de 17 de junio de 2005, Serie C $\mathrm{N}^{\circ} 125$. Disponible en: http://goo.gl/pzREyR Fecha de consulta $31 \mathrm{de}$ mayo de 2016.

Comunidad Indígena Sawhoyamaxa Vs. Paraguay (2006), (Fondo, Reparaciones y Costas), Sentencia de 29 de marzo de 2006, Serie C $\mathrm{N}^{\circ}$ 146. Disponible en: http://goo.gl/vbmIri Fecha de consulta $31 \mathrm{de}$ mayo de 2016.

Pueblo indigena Kichwa de Sarayaku vs. Ecuador (2012), (Fondo y Reparaciones), Sentencia de 27 de junio de 2012, Serie C No 245.

Facultad de Derecho y Ciencias Sociales - Universidad de Valparaíso - Chile 
Disponible en: http://goo.gl/rZhW3T Fecha de consulta 27 de julio de 2016.

Organización Internacional del Trabajo (OIT). Oit (2001): RECLAMACIÓN (artículo 24) - COLOMBIA - C169- 2001

Central Unitaria de Trabadores (CUT). Disponible en: http:// goo.gl/HUrRly Fecha de consulta: 15 de enero de 2016.

Oit (2004): RECLAMACIÓN (artículo 24) - MEXICO - C169 - 2004

Nueve organizaciones de trabajadores. Disponible en: http://goo.gl/ 4ufWJQ Fecha de consulta: 15 de enero de 2016.

Oit (2009): Informe III (1A): Informe de la CEACR. Ginebra. Disponible en: http://goo.gl/NSOiDe Fecha de consulta: 15 de enero de 2016.

\section{TRIBUNAL CONSTITUCIONAL}

Diputados de la República(2000): Tribunal Constitucional, 4 de agosto de 2000 (Requerimiento de inconstitucionalidad Convenio 169 de la Organización del Trabajo). Rol 309.

Cámara de Diputados (2008): Tribunal Constitucional, 3 de abril de 2008 (Control de constitucionalidad del proyecto de acuerdo aprobatorio relativo al Convenio $\mathrm{N}^{\mathrm{o}}$ 169). Rol 1050.

Senadores de la República (2013): Tribunal Constitucional, 23 de enero de 2013 (Requerimiento de inconstitucionalidad artículo $1^{\circ}$, numerales 20, 3, letra c) y 48 del proyecto de ley incluido en el Boletín No 8091-21). Rol 2387.

\section{TRIBUNALES ORDINARIOS}

* Todas las sentencias citadas fueron recuperadas desde la plataforma web del Poder Judicial de Chile entre marzo de 2015 y marzo de 2016: http://www.pjud.cl/consulta-unificada-de-causas

Asociación Tragun Mapu Maile Allipen contra Comisión Evaluadora Ambiental Región de la Araucanía (2012): Corte Suprema, 8 de junio de 2012. Rol 1602-2012 [apelación de protección].

— ICA Temuco, 20 de enero de 2012. Rol 349-2011.

Comunidad Agrícola Los Huasco Altinos con Comisión de Evaluación Región de Atacama (2012): Corte Suprema, 27 de abril de 2012. Rol 2211-2012 [acción de protección].

_ ICA Antofagasta, 17 de febrero de 2012. Rol 618-2011.

Revista de Ciencias Sociales - Número 69 (2016) - Universidad de Valparaíso - ISSN 0716-7725-Valparaíso, Chile 
Comunidad Antu Lafquen de Huentetique contra COREMA Región de Los Lagos (2012): Corte Suprema, 22 de marzo de 2012. Rol 10.090-2011 [acción de protección].

ICA Puerto Montt, 11 de octubre de 2011. Rol 239-2011.

Comunidad Aymara de Parca y otros contra Comisión Regional de Evaluación Ambiental (2014): Corte Suprema, 30 de octubre de 2014.

Rol 22.461-2014 [acción de protección].

Comunidad Diaguita Yastai de Junta de Valeriano y otros contra Comisión de Evaluación Ambiental (2014): Corte Suprema, 7 de octubre de 2014. Rol 11.299-2014 [acción de protección].

Comunidad Felipe Nitrihuala con COREMA Región de la Araucanía (2011): Corte Suprema, 17 de junio de 2011. Rol 4289-2011 [acción de protección].

- ICA Temuco, 3 de mayo de 2011. Rol 150-2011.

Comunidad Huenchullan contra Ministerio de Energía (2013): 17 de enero de 2013. Rol 9526-2012 [acción de protección].

—_ ICA Santiago, 16 de noviembre de 2012. Rol 9431-2012.

Comunidad Manquilef Hueche contra Ministerio de Energía (2013): Corte Suprema, 24 de enero de 2013. Rol 495-2013 [acción de protección].

—_ ICA Santiago, 16 de noviembre de 2012. Rol 12.652-2012.

Consejero Territorial Alto Tarapacá y otros contra Directora Servicio de Evaluación Ambiental Región de Tarapacá (2012): Corte Suprema, 30 de marzo de 2012. Rol 11.040-2011 [acción de protección].

- ICA Iquique, 8 de noviembre de 2011. Rol 472-2011.

Consejo de Pueblos Atacameños contra COREMA Región de Antofagasta (2011): Corte Suprema, 13 de julio de 2011. Rol 258-2011 [acción de protección].

_- ICA Antofagasta, 21 de diciembre de 2010. Rol 782-2010.

Consejo de Pueblos Atacameños y otros con Comisión Regional de Evaluación Ambiental (2014): Corte Suprema 22 de mayo de 2014. Rol 16.817-2013 [acción de protección].

Cruz y otros contra Ministerio de Energía (2013): Corte Suprema, 17 de enero de 2013. Rol 9527-2012 [acción de protección].

__ ICA Santiago, 16 de noviembre de 2012. Rol 12.533-2012.

Facultad de Derecho y Ciencias Sociales - Universidad de Valparaíso - Chile 
Grunewald Condori y otros contra Intendente de la Región de Arica y Parinacota (2011): Corte Suprema, 2 de diciembre de 2012. Rol 10.8692011 [acción de protección].

- ICA Arica, 2 de noviembre de 2011. Rol 359-2011.

Huilcaman y otros con Huaracan (2009): Corte Suprema, 8 de septiembre de 2009. Rol 5940-2009 [acción de protección].

— ICA Temuco, 27 de julio de 2009. Rol 769-2009.

Gutiérrez con Comité de Ministros (2015): Corte Suprema, 29 de septiembre de 2015. Rol 10.349-2015 [acción de protección].

_ ICA Santiago, 17 de julio de 2015. Rol 73.562-2014.

Lof Trankura y otros contra Comisión Evaluadora Ambiental de la Araucanía (2015): Corte Suprema, 29 de diciembre de 2015. Rol 33.1542015 [acción de protección].

— ICA Temuco, 16 de noviembre de 2015. Rol 3956-2015.

Manquepillan con COREMA Región de los Ríos (2011): Corte Suprema, 4 de enero de 2011. Rol 6062-2010 [acción de protección].

— ICA Valdivia, 4 de agosto de 2010. Rol 243-2010.

Marifilo con Ministerio de Obras Públicas (2014): Corte Suprema, 22 de abril de 2014. Rol 1515-2014 [acción de protección].

—_ ICA Valdivia, 3 de enero de 2014. Rol 2149-2013.

Municipalidad de Putre con COREMA Región de Arica y Parinacota (2011): Corte Suprema, 16 de junio de 2011. Rol 2262-2011

[acción de protección].

— ICA Arica, 4 de marzo de 2011. Rol 9-2011.

Nahuelpan y otros con COREMA de Los Ríos (2010): Corte Suprema, 14 de octubre de 2010. Rol 4078-2010 [acción de protección].

_ ICA Valdivia, 26 de mayo de 2010. Rol 148-2010.

Papic con Comunidad Indígena Aymara Chusmiza Usmagama (2009):

Corte Suprema, 25 de noviembre de 2009. Rol 2840-2008 [recurso

de casación forma y fondo].

Pueblos Indígenas Unidos de la Cuenca de Tarapacá con Servicio de Evaluación de Impacto Ambiental (2016): Corte Suprema, 19 de mayo de 2016. Rol 817-2016 [recurso de casación forma y fondo].

— Segundo Tribunal Ambiental, 1 de diciembre de 2015. Rol 542014 [reclamación ambiental]. 
Puelman y otro con COREMA Región de la Araucanía (2010): Corte Suprema, 17 de mayo de 2010. Rol 1525-2010 [acción de protección].

- ICA Temuco, 29 de enero de 2010. Rol 1705-2009.

Reyes Alcaman y otros con Ministerio de Obras Públicas (2011): Corte

Suprema, 6 de mayo de 2011. Rol 1608-2011 [acción de protección].

_- ICA Santiago, 31 de enero de 2011. Rol 1794-2010.

Troncoso y Mamani con Sociedad Inversiones e Inmobiliaria Villa Nueva

S.A. (2013): Corte Suprema, 26 de septiembre de 2013. Rol 3010-

2013 [acción de protección].

—_ ICA Antofagasta, 15 de abril de 2013. Rol 1414-2012.

Vargas contra Servicio de Evaluación Ambiental(2014): Corte Suprema, 12 de agosto de 2014. Rol 17.120-2013 [acción de protección].

ICA Arica, 25 de noviembre de 2013. Rol 182-2013.

Vera Millaquen con Empresa Pesquera Los Fiordos Ltda. (2010); Corte Suprema, 15 de septiembre de 2010. Rol 5757-2010 [acción de protección].

__ ICA Puerto Montt, 27 de julio de 2010. Rol 36-2010.

Facultad de Derecho y Ciencias Sociales - Universidad de Valparaíso - Chile 